\title{
Some Thoughts on Treatment of Tunnel Diseases in High Altitude and Cold Regions
}

\author{
Cun Fang Zhu ${ }^{1}$, Wang Kun ${ }^{2,3^{*}}$, and LuShi Wang ${ }^{2,3}$ \\ ${ }^{1}$ Qinghai Local Railway Construction Investment Co., Ltd., Xining, 810008 \\ ${ }^{2}$ China Merchants Chongqing Communications Technology Research \& Design Institute Co., Ltd., Chongqing, 400067 \\ ${ }^{3}$ National Engineering Laboratory For Highway Tunnel Construction Technology, Chongqing 400067
}

\begin{abstract}
Tunnels in high-altitude areas in our country have a wide distribution range and a large number. Due to factors such as complex engineering geological conditions and harsh operating environments, tunnels often face severe freezing damage during operation. The freezing damage of tunnels in cold regions often seriously threatens the safety of vehicles. The service level of the tunnel also decreases. This article reviews the typical diseases and manifestations of tunnels in cold regions, this paper analyzes the main causes affecting the freezing damage of tunnels, and finally introduces the common treatment measures for several common diseases of tunnels in cold areas with high altitude, summarizes the main problems of existing treatment measures, and puts forward corresponding improvement measures, which can provide guidance for similar treatment.
\end{abstract}

\section{Introduction}

The freezing damage of tunnels in high-altitude areas is an issue worthy of much attention. Any tunnel located in an area where seasonal freezing occurs may suffer from freezing damage. In high-altitude and severe cold areas, tunnel freezing damage is more common, more widespread and more likely to occur. The permafrost area and the seasonal frozen soil area in China are $2.15 \times 106 \mathrm{~km}^{2}$ and $5.14 \times 106 \mathrm{~km}^{2}$, accounting for $22.4 \%$ and $75.9 \%$ respectively ${ }^{[1]}$. They are mainly distributed in Northwest China, Southwest China, North China, Northeast China and areas with higher latitudes ${ }^{[2]}$. With the continuous development of tunnel engineering in China, the demand of transportation infrastructure is increasing, and there are more and more tunnels passing through frozen soil strata. Surrounding rocks and groundwater swell due to freezing, and tunnel lining, affected by frost heaving, is prone to serious freezing damage such as lining crack and leakage, which brings great challenges to the operation and maintenance of tunnels and increases the economic cost ${ }^{[3]}{ }^{[4]}$. Therefore, how to effectively avoid freezing damage and effectively treat frozen tunnels is a major difficulty challenging the engineering circles.

\section{Investigation on Freezing Damage of Tunnel Projects in High-Altitude Areas}

Scholars at home and abroad have carried out a lot of research work on the freezing damage of tunnels in in cold areas ${ }^{[5]-[11]}$. In Russia, Japan, northern Europe and
North America, frozen soil is widely distributed, and tunnel freezing damage is very common. If the freezing damage is very serious, it will lead to the failure of the main lining structures, which will bring potential safety threats during the tunnel operation. In China, there are many tunnel freezing damage cases, such as Zhegushan Tunnel, Gansu Wushaoling Tunnel, Dabanshan Tunnel and Que'ershan Tunnel. It can be seen that the prevention and control of tunnel freezing damage is a very important subject. This paper first summarizes the main manifestations of tunnel freezing damage on the basis of previous studies. Then, based on a large number of engineering examples, the distribution of freezing damage of tunnels in high-altitude and cold areas in China is summarized through on-site inspection and investigation, and the common treatment schemes for tunnel freezing damage in cold areas are summarized. Besides, some treatment schemes are improved to ensure a better treatment effect.

In China, tunnels in high-altitude areas are mainly distributed in the Qinghai-Tibet Plateau and its marginal areas. The representative tunnels and diseases listed in Table 1 are based on the author's field investigation.

Table 1. Typical High-Altitude Tunnels and Diseases in China.

\begin{tabular}{|c|c|c|c|c|}
\hline S/N & Tunnel name & $\begin{array}{c}\text { Length } \\
/ \mathrm{m}\end{array}$ & $\begin{array}{c}\text { Altitude } \\
/ \mathrm{m}\end{array}$ & $\begin{array}{c}\text { Diseases } \\
\text { manifested }\end{array}$ \\
\hline 1 & $\begin{array}{c}\text { Qingshashan } \\
\text { Tunnel }\end{array}$ & 3355 & 3005 & $\begin{array}{c}\text { Pavement icing, } \\
\text { lining cracking } \\
\text { and ice } \\
\text { covering on } \\
\text { lining }\end{array}$ \\
\hline
\end{tabular}

\footnotetext{
* Corresponding author: wk@cmhk.com
} 


\begin{tabular}{|c|c|c|c|c|}
\hline 2 & $\begin{array}{l}\text { Ri'erlangshan } \\
\text { Tunnel }\end{array}$ & 1625 & 3477 & $\begin{array}{l}\text { Lining seepage } \\
\text { and icing, } \\
\text { lining cracking, } \\
\text { pavement and } \\
\text { drainage ditch } \\
\text { icing }\end{array}$ \\
\hline 3 & $\begin{array}{l}\text { Dabanshan } \\
\text { Tunnel }\end{array}$ & 1530 & 3793 & $\begin{array}{l}\text { Icing in the } \\
\text { snow-shed } \\
\text { tunnel, cracking } \\
\text { and damage of } \\
\text { lining, breakage } \\
\text { and freezing of } \\
\text { tunnel portal } \\
\text { interception } \\
\text { system, crack } \\
\text { leakage and ice } \\
\text { covering and } \\
\text { pavement } \\
\text { damage and } \\
\text { collapse }\end{array}$ \\
\hline 4 & $\begin{array}{l}\text { Milashan } \\
\text { Tunnel }\end{array}$ & 5727 & 4740 & $\begin{array}{l}\text { Ice covering on } \\
\text { lining and icing } \\
\text { on pavement }\end{array}$ \\
\hline 5 & $\begin{array}{l}\text { Lajishan } \\
\text { Tunnel }\end{array}$ & 5564 & $\begin{array}{l}3200- \\
4100\end{array}$ & $\begin{array}{l}\text { Breakage of } \\
\text { roof ditches, } \\
\text { icing of portal } \\
\text { pipe trenches at } \\
\text { tunnel, lining } \\
\text { cracking, lining } \\
\text { seepage and } \\
\text { icing, ditch } \\
\text { icing, and } \\
\text { pavement } \\
\text { collapse. }\end{array}$ \\
\hline 6 & $\begin{array}{l}\text { Yankoushan } \\
\text { Tunnel }\end{array}$ & 4032 & 4330 & $\begin{array}{l}\text { Longitudinal } \\
\text { manhole icing, } \\
\text { ice covering on } \\
\text { lining and icing } \\
\text { on pavement }\end{array}$ \\
\hline 7 & $\begin{array}{l}\text { Tongtianhe } \\
\text { Tunnel }\end{array}$ & 3032 & 3580 & $\begin{array}{l}\text { Longitudinal } \\
\text { manhole icing, } \\
\text { ice covering on } \\
\text { lining and icing } \\
\text { on pavement }\end{array}$ \\
\hline
\end{tabular}

Tunnels in high-altitude and cold areas are affected by cold climate. In addition to conventional tunnel diseases, tunnels located in permafrost regions are also subject to special diseases in cold area tunnels, such as cracking and peeling of tunnel lining caused by freezethaw cycles, hollowing behind lining, icing on side walls and bottom, tunnel portal cracking, etc. The occurrence of diseases may lead to intrusion, which brings great troubles to the operation of tunnels. There is great difficulty in dealing with the diseases, which will cause a lot of resource and economic losses. In essence, the freezing damage of tunnels in high-altitude and cold areas can be classified into the following categories:

\subsection{Cracking and spalling of concrete lining structure}

The freezing of groundwater behind lining will cause volume expansion. When the expansion of volume is transferred to the lining structure, the stress on the lining structure will increase, which will lead to lining damage and bulging, surface cracking and spalling and even the overall collapse of lining.

The main hazards of cracking and spalling of lining structure include: (1) Great reduction in the bearing capacity of lining structure to carry surrounding rocks; (2) Invasion into tunnel clearance, thus endangering the traffic safety; (3) Provision of a leakage channel for groundwater behind the lining after cracking, which further leads to ice covering on lining and icing on pavement; (4) Aggravation of frost heaving cracking of lining because of freeze-thaw cycles.
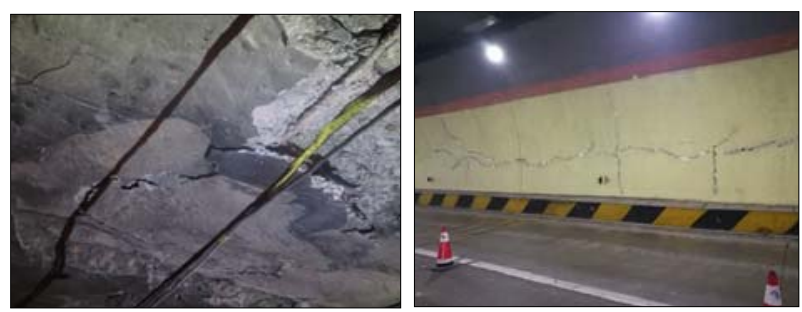

Fig. 1. Cracking and Spalling of Concrete Lining Structure.

\subsection{Ice covering on lining and icing on pavement}

The lining waterproofing is damaged, and the groundwater flows out from the defect, which condenses on the side wall or top of the lining to form icicles, and gathers on the pavement to result in icing.

The main hazards of ice covering on lining and icing on pavement include: (1) The icicles hanging on the lining will invade the tunnel clearance and affect driving; (2) The seeped water drops to the pavement, which, after icing, leads to the deterioration of the driving environment in the tunnel, reduces the road adhesion of the tire and greatly threatens the driving safety; (3) The accumulated water seeps into the pavement, which, after freeze-thaw cycles, damages the pavement base structure and leads to pavement damage and collapse, etc.
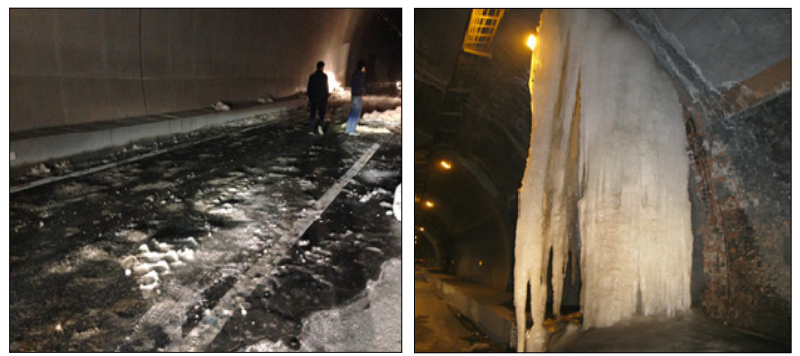

Fig. 2. Pavement Icing and Ice Covering on Lining in Tunnel.

\subsection{Icing of in-tunnel pipe trenches and longitudinal manholes}

The surface water in tunnel is developed, and after 
infiltration, the surface water is not discharged sufficiently through pipe trenches. Low temperature causes freezing of in-tunnel pipe trenches and longitudinal manholes.

Icing hazards of in-tunnel pipe trenches and longitudinal blind drain manholes: (1) The pipe trenches in tunnel is damaged after repeated action of frost heaving force; (2) Squeeze the lining structure and pavement structure, causing lining structure and pavement diseases; (3) Cause freezing and plugging of longitudinal drainage pipes, resulting in poor drainage behind the lining, leading to the increase of water pressure, and eventually causing water seepage to pass through waterproof boards and secondary lining.
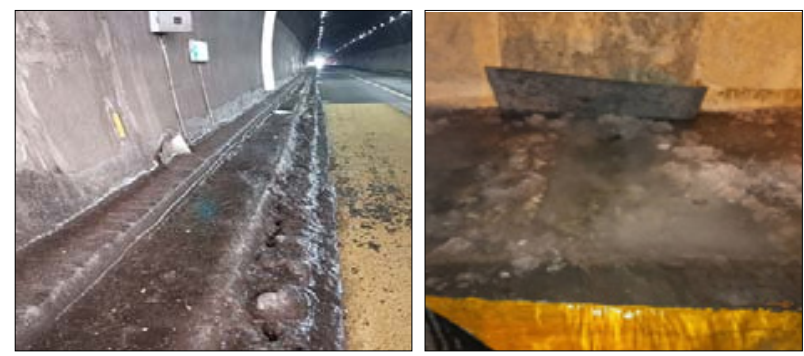

Fig. 3. Freezing of Tunnel Pipe Trenches and Longitudinal Blind Drain Manhole.

\subsection{Breakage and freezing of tunnel portal interception system}

Breakage and freezing of tunnel portal interception system: Intercepting ditches are located in the natural conditions outside tunnel where the temperature is low and the temperature difference is large, so they are easy to damage.

Main hazards of breakage and freezing of tunnel portal interception system: If intercepting ditches are frozen and finally damaged, the surface water on tunnel roof cannot be collected and discharged, which makes the surface overflow. The surface water may penetrate into the lining, causing a series of diseases in the tunnel.
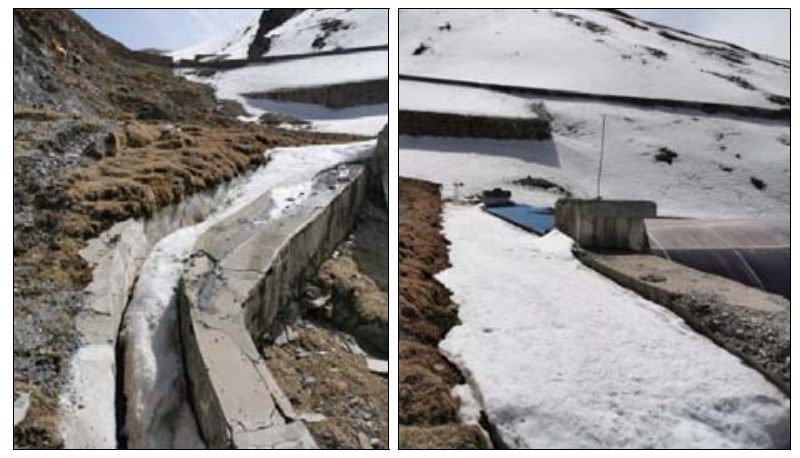

Fig. 4. Freezing of Roof Intercepting Ditches.

\section{Analysis of Causes for Main Diseases in High-altitude Tunnels}

Combined with the comprehensive analysis of years of tunnel monitoring results, site survey, tunnel site conditions, etc., the main disease of high-altitude tunnels is freezing damage, and the main influencing factors are temperature and groundwater. The interaction between the two causes many diseases in high-altitude tunnels.

\subsection{Groundwater}

Groundwater refers to various forms of gravity water buried under the ground surface. Its content is determined by the nature and structure of surrounding rock, and its recharge and discharge conditions are affected by climate and topography. The completion and operation of tunnels have changed the original flow direction of groundwater. When the groundwater drainage is blocked, the surface replenishment increases, the tunnel drainage system is blocked or the drainage capacity is insufficient, water will accumulate behind the lining, resulting in an increase in water pressure. Finally, leakage from tunnel waterproofing, lining cracking, pavement seepage, basement softening and collapse will occur at the location where the tunnel waterproofing and drainage facilities are weak.

\subsection{Low temperature}

For a high-altitude tunnel, the groundwater temperature in the surrounding rock of the tunnel is low. If the water content in the surrounding rock is high, the drainage system in the tunnel fails, and there is a large amount of static water in the pavement, pipe trenches and drainage pipes, the low temperature will freeze the water and cause volume expansion. Under the effect of frost heaving, the roadside ditch and central ditch will squeeze the ditch and pavement structure, leading to deformation or damage of the ditch. Repeated freezethaw cycles will greatly damage the structure and eventually cause damage to the pavement and lining structure. After freezing, the surrounding rock behind will expand in volume, and when it is restrained by the lining structure and surrounding rock, it will produce frost heaving force, which will squeeze the lining structure and finally produce lining cracks. When the water seepage in the lining cracks freezes, the corresponding crack width will increase after multiple freezing and thawing, and repeated freeze-thaw cycles will eventually cause the tunnel lining to crack.

\section{Treatment Schemes and Improvement Measures for Common Diseases of High-Altitude Tunnels}

In view of the common diseases of high-altitude tunnels mentioned above, a summary of the commonly used treatment measures is made first, including crack treatment, leakage treatment, lining reinforcement treatment, improvement of drainage system, addition of insulation layer and other measures.

\subsection{Crack plugging}

Crack plugging means that the lining cracks with a width 
not less than $0.5 \mathrm{~mm}$ are slotted and filled before glue injection. The preferred slot type is inverted trapezoid. The depth and width of the slots should be no less than $20 \mathrm{~mm}$ and $15 \mathrm{~mm}$ respectively, and the preferred filling material should be polymer modified cement mortar.

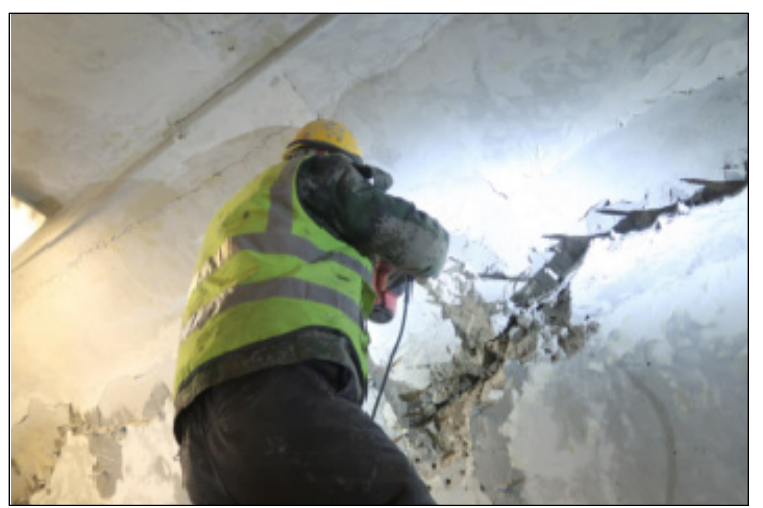

Fig. 5. Slotting and Plugging of Cracks.

At present, slotting-plugging scheme is widely used. When slotting, it is difficult to control the construction quality. If the slot is made too large, it will destroy the integrity of the lining structure and increase the structural safety risk. In addition, when polymer modified cement mortar is used to plug cracks, the construction is difficult and the treatment quality is difficult to guarantee. When polymer cement mortar is squeezed out under the frost heaving force, it will be a great potential safety hazard.

In this paper, the treatment method has been improved and changed to glue injection and plugging. Firstly, use high-pressure water gun to clean the cracks and remove the residues in the cracks; secondly, drill glue injection holes at the edge of the cracks at a certain interval; after drilling, clean the holes and plant glue injection nozzles; apply sealing glue at the cracks (seal the glue nozzles) to seal the crack surface; finally, inject epoxy resin glue through the glue injection nozzles.

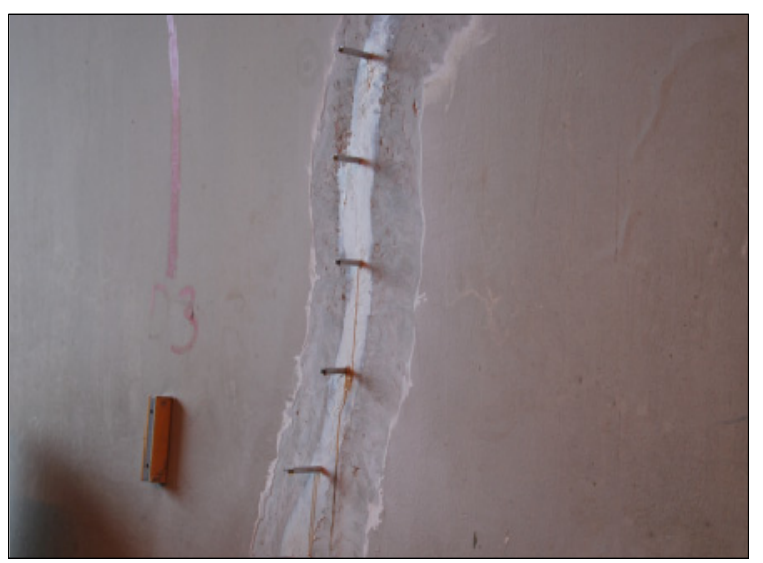

Fig. 6. Glue Injection and Sealing of Cracks.

\subsection{Treatment of water leakage}

For the location where water seepage is concentrated, the widely used method at present is to divert water by slotting and burying pipe, that is, cutting inverted trapezoidal slots circumferentially along the lining at the location of concentrated seepage and at the construction joints, and installing semi-cut pipes and insulation boards to complete the leakage drainage of lining.

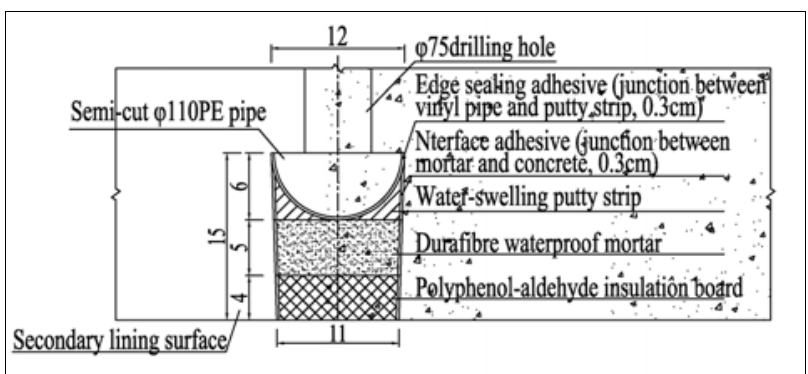

Fig. 7. Cross-Sectional View of Leakage Treatment by Slotting and Burying Pipes.

For the inverted trapezoidal drainage scheme by slotting and burying pipes that is adopted currently, due to the small slot size, it is difficult to cut the inverted trapezoidal slots to a satisfactory degree. Moreover, for complex construction process in a limited space, there is difficulty in controlling the construction, too much emphasis is placed on "drainage", and the lining glue injection sealing is not done or not completed to a satisfactory degree, so it is easy to lead to recurrence of water seepage; In addition, the partial-whole relationship is often not handled properly during the treatment process, the scope of treatment is not enough, and there is no consideration of the fact that the position of the disease may change with the passage of time, resulting in the development of leakage disease around.

Based on the above problems, this paper puts forward that drainage by buried pipes should be used in conjunction with drainage holes and lining grouting (glue) to stop water; as the semi-cut pipes are finally led into the tunnel side ditch or the central ditches, the drainage and dredging of the roadside and the central ditches should be strengthened; in the case of serious leakage, it is necessary to discharge and drain the water, inject glue for plugging, and redo the waterproofing and drainage system; strengthen the fine construction management of water seepage treatment; select the treatment scope reasonably according to the specific distribution of water seepage sections.
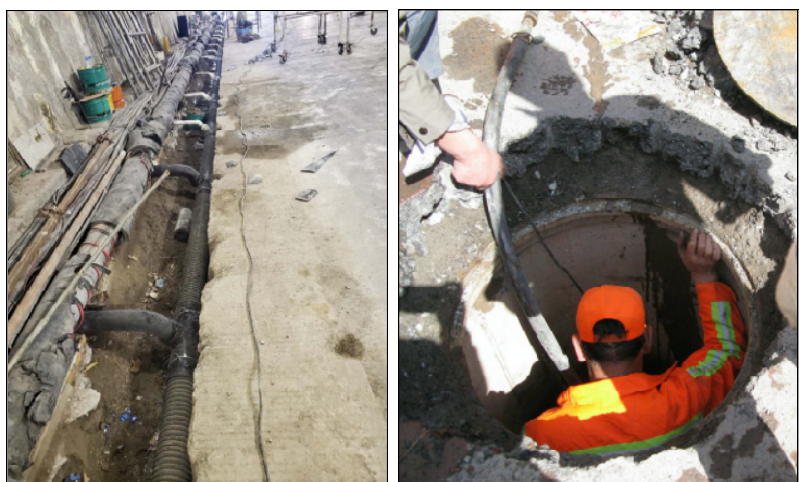

Fig. 8. Dredging of Roadside and Central Ditches.

When treating tunnels with large groundwater content and provided with drainage tunnels, the transverse drainage tunnels can be infilled and 
lengthened to achieve the effect of effectively diversion of the groundwater.

For sections with water seepage and icing caused by low temperature all the year round, the slotting drainage can be used in combination with the measures of electric tracing heating and insulation, and adding insulation layer to ensure the treatment effect. For the section with serious water leakage in the shallow buried section at the tunnel portal, waterproofing and drainage treatment can be carried out on the ground surface over the tunnel roof to reduce the probability of surface water infiltration.
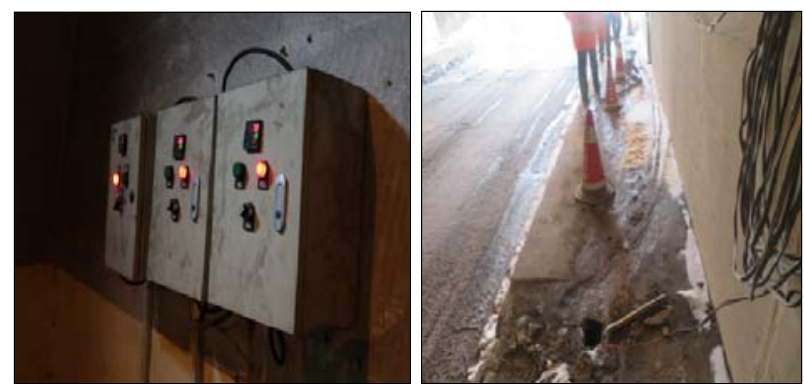

Fig. 9. Electric Tracing Heating System .

\subsection{Treatment of pavement seepage and icing}

For water seepage on the pavement surface, the commonly used method is to cut slots in the upper part of the pavement slab and cover them with channel steel or steel plate to drain the water to the roadside ditch (with the side ditch covered with insulation board and mortar, and equipped, depending on the circumstances, with electric heat tracing). After being drained to a certain distance downstream, it will be collected to the central ditch manhole.

The main problems of the scheme include: The roadside ditch is occupied, the function of draining the surface water on the pavement is lost, the mortar of insulation board has been damaged, and the slots cut in some pavement slabs are concentrated, which affects the integrity and driving comfort; the channel steel or steel plate is on the upper part of the pavement, which is easy to be damaged due to vehicle rolling, and the water seepage is easy to redevelop to the pavement; for low temperature sections, as the slots cut are shallow, the expansion of water in volume after freezing can easily cause the steel plate to be pushed up, resulting in the failure of treatment measures and increasing the potential hazards to driving safety.

In view of the above problems, the treatment way of setting blind drain on pavement, that is, deepening the cut depth of the slots and directly leading the accumulated water under the pavement to the central ditch, can eliminate the potential hazard of occupying the roadside ditch and accumulated water freezing. In tunnels provided with drainage tunnels, drainage holes are drilled at a certain distance along the center line of the pavement to the cold-proof drainage tunnel to establish the hydraulic connection between the invert filling and the cold-proof drainage tunnel, so as to remove the accumulated water inside the invert and eliminate the accumulated water in the central drainage ditches seeping from the foot of side walls.

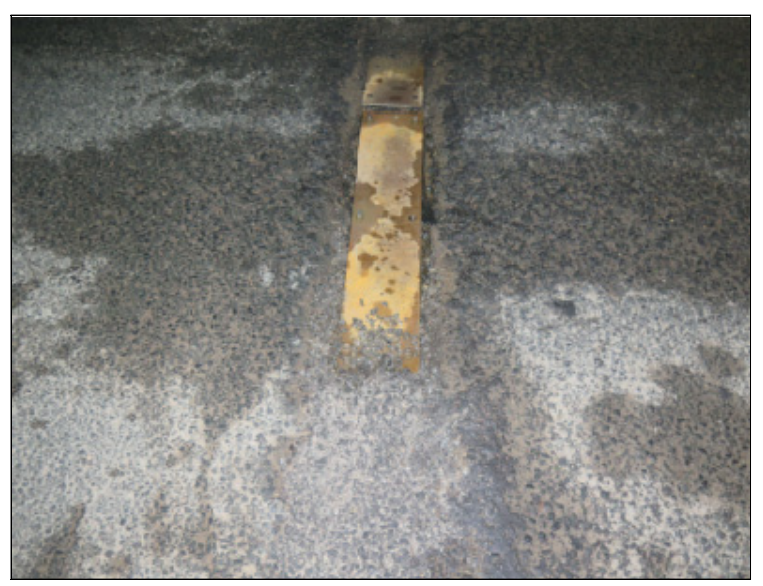

Fig. 10. Design of Pavement Slotting and Drainage.

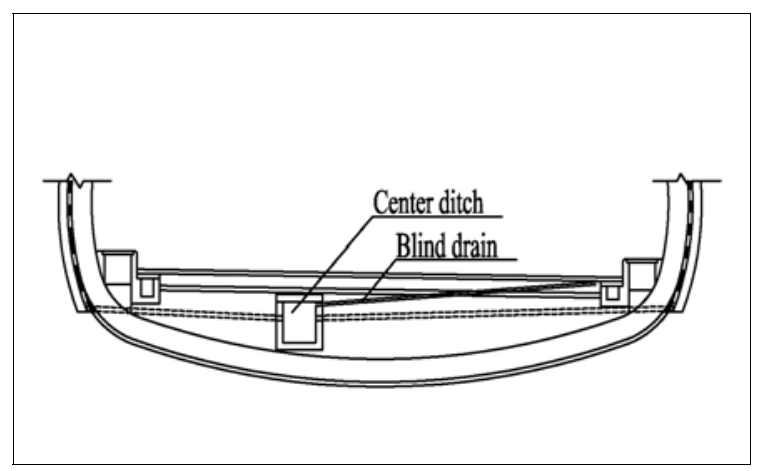

Fig. 11. Design of Blind Drain under pavement.

When the water seepage is caused by the infiltration of groundwater under the invert or pavement base, at present, the treatment measures of reconstructing the structure under the pavement and the central drainage ditch are mostly adopted at present.

Main problems of this scheme: From the perspective of some invert demolition and replacement projects that have been implemented, the actual elevation of the central ditch is, due to the quality defects at the tunnel bottom, higher than the original design. After the drainage system of the invert and tunnel are repaired according to the original design standards, the problems of upstream hydraulic drop and downstream water accumulation will arise at the junction between the old and new central ditches. Water accumulation will deteriorate the surrounding rock for a long time and cause diseases, which is not conducive to long-term stability.

Regarding the above problems, this paper proposes that the elevation and longitudinal slope of the existing central ditch at both ends should be checked during the actual treatment construction, and the new central ditch should be connected with the existing one in a gradient manner according to the actual conditions. No water accumulation section is allowed at the junction between the old and new central ditches downstream. 


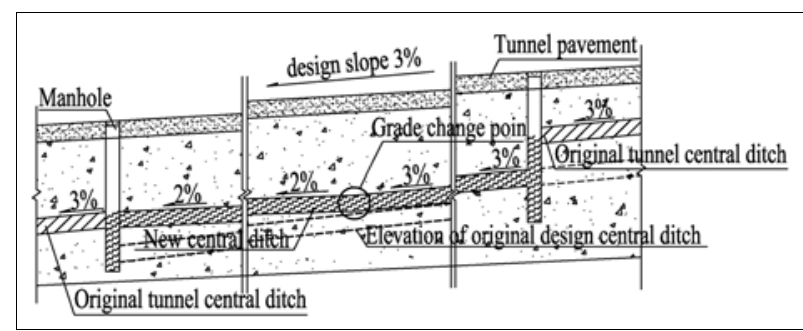

Fig. 12. Connection of Central Ditches in Treatment Section.

\section{Engineering Examples}

Qinghai Province is located in the northwest inland of China, with an average altitude of over $3,000 \mathrm{~m}$. The annual average temperature of various regions in the province is between $-5.1 \sim 9.0^{\circ} \mathrm{C}$. In recent years, many tunnels in Xining City, Haidong City, Hainan Tibetan Autonomous Prefecture and Haixi Mongolian Autonomous Prefecture of Qinghai Province have completed the construction for disease treatment, and various diseases have been treated with the schemes mentioned above, which has obvious treatment effect.

Table 2. List of Upgrading and Reconstruction of Some Tunnels in Qinghai (Partial)

\begin{tabular}{|c|c|c|c|}
\hline $\begin{array}{l}. \mathrm{S} / \\
\mathrm{N}\end{array}$ & Tunnel name & Main diseases & Treatment measures \\
\hline 1 & $\begin{array}{c}\text { Yankoushan } \\
\text { Tunnel }\end{array}$ & $\begin{array}{l}\text { Pavement } \\
\text { seepage and } \\
\text { icing }\end{array}$ & $\begin{array}{l}\text { Dredge the drainage } \\
\text { system, set up the } \\
\text { transverse blind } \\
\text { drain under the } \\
\text { pavement, and } \\
\text { introduce the central } \\
\text { ditch }\end{array}$ \\
\hline 2 & $\begin{array}{l}\text { Tongtianhe } \\
\text { Tunnel }\end{array}$ & $\begin{array}{l}\text { Pavement } \\
\text { seepage and } \\
\text { icing }\end{array}$ & $\begin{array}{l}\text { Dredge the drainage } \\
\text { system, set up the } \\
\text { transverse blind } \\
\text { drain under the } \\
\text { pavement, and } \\
\text { introduce the central } \\
\text { ditch }\end{array}$ \\
\hline 3 & $\begin{array}{l}\text { Lajishan } \\
\text { Tunnel }\end{array}$ & $\begin{array}{c}\text { Lining } \\
\text { leakage, ice } \\
\text { covering and } \\
\text { cracking, } \\
\text { pavement } \\
\text { depression }\end{array}$ & $\begin{array}{l}\text { Slotting and } \\
\text { drainage, glue } \\
\text { injection and } \\
\text { sealing, base } \\
\text { grouting, adding } \\
\text { invert, etc. }\end{array}$ \\
\hline 4 & $\begin{array}{l}\text { Liushaogou } \\
\text { Tunnel }\end{array}$ & $\begin{array}{l}\text { Lining } \\
\text { leakage, ice } \\
\text { covering and } \\
\text { cracking, roof } \\
\text { ditch damage, } \\
\text { cable trench } \\
\text { leakage, and } \\
\text { pavement icing }\end{array}$ & $\begin{array}{c}\text { Slotting and } \\
\text { drainage, glue } \\
\text { injection and } \\
\text { sealing, building } \\
\text { new roof } \\
\text { intercepting ditch, } \\
\text { and dredging the } \\
\text { drainage system }\end{array}$ \\
\hline 5 & $\begin{array}{c}\text { Dabanshan } \\
\text { Tunnel }\end{array}$ & $\begin{array}{l}\text { Lining leakage } \\
\text { and ice } \\
\text { covering }\end{array}$ & $\begin{array}{l}\text { Slotting and } \\
\text { drainage }\end{array}$ \\
\hline
\end{tabular}

\section{Conclusions}

Many diseases of tunnels in high-altitude and cold areas are caused by freezing damage, and the core reasons for freezing damage of tunnels are mainly low temperature and groundwater, so heat insulation, waterproofing and drainage measures should be taken properly.

In the design and construction stages, three aspects, i.e. temperature condition, surrounding rock condition and hydrological condition, should be considered. Especially the hydrogeology survey should be done effectively. For water-rich sections, specific design or special demonstration should be carried out to ensure the rationality of design and construction and avoid structural damage during operation as much as possible.

In the operation stage, the freezing damage of tunnels in cold areas is mainly manifested as concrete lining structure cracking, spalling, ice covering, icing phenomenon, water gushing from pavement, freezing deformation, etc. The common treatment measures at present have many potential hazards. The improvement measures proposed in this paper for the common treatment measures of several common diseases have been verified in many tunnel treatment practices, and all of them have received good treatment results, so they can be further popularized and used in the treatment of tunnel diseases in high-altitude and cold areas.

\section{Acknowledgments}

This work is jointly supported by the Science and Technology Project of Transportation Department of Qinghai Province (No. 2020-01).

\section{References}

1. Zhou Youwu, Guo Dongxin, Qiu Guoqing. Geocryology in China [M].Beijing:China Science Publishing \& Media.Ltd,2000,1-10

2. Chen Rensheng, Kang Ersi, Wu Lizong, et al. Cold Regions in China. [J].Journal of Glaclology and Geocryology ,2005,27(4): 471-475

3. Sun Wenhao. Study on Frostresisting and Antifeezing Strategies of Extra-long Highway Tunnel in Cold Area. [D].Chengdu: Southwest Jiaotong University, 2006

4. Su Linjun.Prediction and Countermeasure Research of Freezing Damage of Tunnels in Cold Regions[D]. Chengdu: Southwest Jiaotong University, 2007

5. Nie Fengming. Dynamic State of Air Temperature in Rwailway Tunnels in Cold Regions[J]. Journal of Glaclology and Geocryology , 1988,10(4) : 450453

6. Zhang Xuefu, Su Xinmin, Lai Yuanming, et al. Analyzing the Effect of Tunneling on Temperature of Permafrost in the Kunlun Mountains, Tibetan Plateau[J]. Journal of Glaclology and Geocryology , 2003,25(6): 621-627 
7. Chen Jianjiu, Luo Yanbin. Changing Rules of Temperature Field for Tunnel in Cold Area. [J].Journal of Traffic and Transportation Engineering,2008,8(2): 44-48

8. Zhang Dehua, Wang Mengshu, et al. Effect of Frost Heaving on Tunnel Surpporting Systems of Fenghuo Shan Railway Tunnel. [J]. Chinese Journal of Geotechnical Engineering ,2003,25(5): 571-573

9. Wu Jianhui, Liu Ruiquan, Wang Liancheng. Deep Hole Grouting Water Plugging Reinforcement Process in Shallow-buried Water-rich Zone for Tunnels in Cold Area[J]. Journal of Highway and Transportation Research and Development, 2016,32(05):91-95

10. Zhang Zhuo. Insulation and Antifreeze Design of Deqin Tunnel on Xiangde Second-class Highway in Yunnan Province[J]. Journal of Highway and Transportation Research and Development, 2014(01):107-110

11. Qin Feng, Hu Juyi. Key Points of Freezing Damage Prevention and Control of Highway Tunnel in Cold Area[C]. Proceedings of the Seventh Annual Conference of the Maintenance and Management Branch of China Highway Society, 14-20 